\title{
State Gun Control Laws, Gun Ownership and the Supply of Homicide Organ Donors
}

\section{Authors: Firat Bilgel}

(C) This manuscript version is made available under the CC-BY-NC-ND 4.0 license.

Bilgel, Firat. "State Gun Control Laws, Gun Ownership and the Supply of Homicide Organ

Donors." International Review of Law and Economics 63 (September 2020): 105925. doi:10.1016/ j.irle.2020.105925.

Made available through Montana State University's ScholarWorks 


\title{
State Gun Control Laws, Gun Ownership and the Supply of Homicide Organ Donors
}

\author{
Firat Bilgel
}

\begin{abstract}
The likelihood of being a potential deceased organ donor is higher for individuals who have been exposed to situations typically characterized by a severe head trauma or stroke that result in brain death. Employing count data models that account for overdispersion and/or excessive counts of zeros, this paper assesses the unintended consequences of enforcing stricter gun control laws and the effects of gun ownership on homicide organ donor supply in the United States using county data for the period 20092015. The findings confirm the transplantation paradox hypothesis that stricter gun control laws reduce the expected cases of gun homicides and thereby reduce deceased organ donor supply and exacerbate the organ shortage. The findings are robust to several measures of the strength of gun control laws, restricted samples and spurious outcome variables. However, the direction of the impact of gun ownership levels on homicide organ donor supply proved to be inconclusive.
\end{abstract}

Keywords: Organ donation; state gun control laws; homicide; negative binomial; overdispersion JEL classification: I18, C21, C25, K14, K32

*Department of Economics, MEF University, Ayazağa Cd. no.4 34396 Istanbul Turkey. Email: bilgelf@mef.edu.tr 


\section{Introduction}

The likelihood of dying under circumstances that would render an individual's organs suitable for transplantation is very low. Estimates show that the probability that an individual in the 18-79 age group will become a potential donor at some point during her lifetime is 0.0028 (Howard and Byrne, 2007). The period that leads to organ recovery from a deceased individual is extremely complex and layered. Although there are exceptions (e.g. non-heart beating donation), the irreversible cessation of all functions of the entire brain including the brain stem, known as brain-death, is a prerequisite for deceased organ donation. The determination of brain death and therefore the identification of a potential donor is typically contingent upon the individual to go through a cerebrovascular injury (i.e. stroke, aneurysm), severe oxygen deprivation or a severe head trauma (i.e. motorcycle crash, gunshot wound) that otherwise leave visceral organs free of physical damage. Setting aside medical compatibility and consent issues, victims of fatal motor vehicle accidents (MVA), fatal firearm incidents and cerebrovascular diseases (CVD) are therefore suitable donor candidates.

The controversy is that some of these circumstances leading to the death of the individual do not occur naturally and can be prevented by large-scale policy interventions. Examples include mental health parity laws that provide insurance coverage for mental health treatment (Lang, 2013), state motorcycle helmet laws that aim to reduce crash fatalities due to helmetless riding (Peng et al., 2017) and gun control laws that aim to reduce gun-related fatalities (Lee et al., 2017). None of these interventions intend to affect organ donor supply. However, the requirement of the death of an individual in such a way that would render her organs suitable for donation to save someone else's life represents a public health paradox and these large-scale policy interventions might have the unintended consequence of reducing an already low organ donor supply (Annas, 1988). On page 621, Annas (1988) notes:

"Organ transplantation presents a public health paradox: as motor cycle helmet, seat belt, gun control, drunk-driving, and other safety laws succeed in reducing the number of fatalities among young, healthy individuals, they decrease the number of potential organ donors, and exacerbate the "organ shortage". This, in turn, often leads to the death of others that could have been prevented by organ transplantation. It is the requirement of the death of one person before the life of another can be saved or improved that makes organ transplantation unique, and that ensures that the attitudes of both the public and health care professionals toward it will always be profoundly ambivalent."

Since the likelihood of brain death is higher for individuals who are exposed to severe head trauma and the declaration of brain-death is a prerequisite for most cases for deceased donor organ recovery, the unintended 
consequence of such regulations is that they might also reduce the pool of organs available for transplantation. Therefore regional variation in the strength of gun control laws may affect organ donors from victims of homicide if variations in homicide rates significantly impact the supply of homicide organ donors. Employing count data models that account for overdispersion and/or excessive counts of zeros in the data, this paper assesses such unintended consequences of enforcing stricter gun control laws on deceased donor supply in the United States for the period of 2009-2015.

The findings confirm the transplantation paradox hypothesis: stricter gun control laws reduce the expected cases of gun homicides and thereby reduce deceased organ donor supply and exacerbate the organ shortage. The findings are shown to be robust to interchangeable measures of the strength of gun control laws and to the restriction of the sample to (large) urban counties. Robustness checks also show that gun control laws are not related to the supply of donors who die in circumstances other than homicide and provide further support for the estimates.

Section 2 briefly reviews prior literature on gun control and the impact of legal interventions on organ donation; section 3 invokes negative binomial (NB) and zero-inflated negative binomial (ZINB) models to account for overdispersion in homicides along with excessive counts of zeros in homicide organ donor supply data and section 4 reports the results. Section 5 performs a robustness check to provide support for the effect of gun control laws and gun ownership on homicide organ donor supply by assessing whether gun control laws and gun levels are unrelated to the supply of donors who die in circumstances other than homicide. Section 6 assesses the limitations of the analysis and suggests avenues for future research.

\section{Prior Literature}

A niche literature in the United States exclusively focused on the impact of legal interventions on organ donation. Boulware et al. (2008); Wellington and Sayre (2011); Venkataramani et al. (2012); Lacetera et al. (2014); Chatterjee et al. (2015) and Bilgel and Galle (2015) assess the effectiveness of tax incentives on living organ donation and Callison and Levin (2016) assesses the effects of first-person consent (FPC) laws and state adoption of organ donor registries on deceased organ donation. Common to all is that the legal intervention is intentionally and specifically designed with the aim of increasing organ donation rates.

On the other hand, a number of legal interventions that are designed to affect seemingly unrelated aspects pertaining to individuals' rights and freedom have shown to play a significant role in affecting the pool of deceased organ donors. Two studies in particular are relevant in terms of testing the "transplantation paradox" hypothesis in the United States. Dickert-Conlin et al. (2011) focus on the causal effect of state motorcycle helmet laws on MVA organ donors and find that MVA organ donors increase by 10 percent 
following a repeal of state motorcycle helmet laws. Fernandez and Lang (2015) assess the causal effect of mental health parity laws on suicide organ donors and find that mental health mandates decrease female suicide donors by 28.4 percent. However, no research has ever been done so far in the United States regarding the effect of state gun control laws on organ donor supply, possibly due to the difficulties in finding reliable cross-sectional time-series data on gun control laws and due to identification problems. This research addresses the first problem by using three novel measures of different sample periods to account for the strength of gun control laws. Second, this study accounts for overdispersion and excessive counts of zeros in the data using NB and ZINB models of gun homicide and homicide organ donor supply. Through an attempt to identify the effect of gun control laws on gun homicides, this study also contributes to some hundred existing studies on the impact of firearms regulations and gun ownership on violence in the United States.

A reasonable starting point is to briefly overview the theory behind gun control in order to better understand how the effects of gun law and gun levels could affect organ donor supply. Fueled by the Lott and Mustard (1997) analysis, gun control debate still remains unresolved with dozens of papers piled up on both sides of the debate. The argument is that increasing gun levels or allowing citizens to carry guns legally could deter crime by arming potential victims and thereby increasing the prospective criminals' risk of facing an armed response (the deterrent effect). The counter argument is that higher gun levels and less restrictive gun control laws that fail to distinguish high-risk groups from the rest of the population could lead to increased fatal incidents when more people are allowed to carry guns (the facilitating effect). If the deterrent (facilitating) effect dominates the facilitating (deterrent) effect, then increasing gun levels would lead to a net decrease (increase) in crime rate. Plausibly, if the only way the law and gun levels could affect homicide organ donors is through their effect on homicide rates, the net effect of gun control laws and gun levels on organ supply is determined by the size of these relative effects.

First, regardless of the level of analysis, studies on the effects of gun ownership on violence in the United States use untested proxies for gun ownership that have low power of representation (Stolzenberg and D'alessio, 2000; Duggan, 2001). Second, most of the existing research in the United States on gun ownership either uses no controls or a small number of covariates or confounders in the relationship between gun policy/gun ownership and homicide rates. In a review of fourty-one studies of the methodological aspects of the relationship between gun ownership and homicide rates, only three studies (Kleck and Patterson, 1993; Kovandzic et al., 2012, 2013) use a valid proxy for gun ownership, accounts for its endogenous nature and includes more than five significant control variables (Kleck, 2015).

Second, a more drastic picture emerges in studies on the effects of gun policy. Only a handful of papers among dozens on the effects of right-to-carry (RTC) or "shall issue" laws or background checks on total or 
gun homicide rates additionally control for gun ownership and use appropriate proxies (Ruddell and Mays, 2005; Kalesan et al., 2016). Among those that control for gun ownership, either the validity of the proxy variables used has not been confirmed (Dezhbakhsh and Rubin, 1998; Rubin and Dezhbakhsh, 2003), or they are not valid proxies in a panel structure (Irvin et al., 2014; Siegel et al., 2017b). ${ }^{1}$

Third, with notable exceptions (Osgood, 2000; Plassmann and Tideman, 2001), studies that focused on gun control as well as those on the impact of legal interventions on organ donation follow Gaussian models with outcome variables specified as rates despite the fact that aggregate crime rates are computed from a small number of cases. The non-negative nature of the underlying data suggests that a least-squares analysis will produce unreliable estimates. These distributional considerations advocate the use of count data models such as the Poisson or the NB and its variants.

This research explicitly addresses all three shortcomings of the prior literature. First, it uses the best, known and tested proxy for county-level gun availability in a cross-sectional analysis: the percentage of gun suicides. Second, the models control for at least fourteen covariates that are thought to predict homicide rates and therefore homicide organ donors other than gun control laws and gun levels. In fact, the number of statistically significant control variables does not fall below six in any of the estimations. Third, the analysis takes into account the non-negative nature of the count data and invokes Poisson-based models that take into account overdispersion in gun homicide and overdispersion and excessive counts of zeros in homicide organ donor data.

\section{$3 \quad$ Empirical Strategy}

Using state-level panel data to assess the impact of gun policy or gun levels on violence has been a popular choice. However, state-level analysis masks intra-state variation in violence, organ donor supply and in their potential causes. For example, states with high violence rates might have high gun ownership, favoring the "more guns, more crime" hypothesis where in fact parts of those states with high violence rates are not the ones with high gun ownership (Kleck et al., 2016). Similarly, states with high homicide rates might have high homicide organ donor supply rates where in fact parts of those states with high homicide rates are not the places with high organ donor recovery rates. The latter type of situations are likely to occur for an optimized management and transportation of the victim to a hospital which may be located in a neighboring county and may have better medical infrastructure and staff to deal with cases of gunshot wound. Especially with respect to deceased organ donor supply recovered from victims of homicide, a state-level analysis is prone to severe aggregation bias since 89 percent of all counties in the contiguous United States did not recover

\footnotetext{
${ }^{1}$ See Hahn et al. (2005) and Lee et al. (2017) for a review on gun control laws and violence and Hepburn and Hemenway (2004) and Kleck (2015) on gun ownership and violence.
} 
a single case of brain death due to homicide in the 2009-2015 period, exhibiting extreme spatial dispersion and negative spatial autocorrelation.

In contrast, a county-level panel analysis would be the gold standard for the current study. However, there are a number of problems associated with the time dimension of such analyses. First, any analysis that deals with the assessment of the effect of either gun policy or gun ownership on homicide rates should properly account for gun levels. In a longitudinal study, there is no valid proxy for gun ownership (Kleck et al., 2016) although a number of research insists that gun suicide ratio as a proxy for gun ownership in cross-sectional settings could still be used in longitudinal settings (Duggan, 2001; Moody and Marvell, 2005). The problem with using gun suicide ratio as a proxy for gun ownership in panel settings is that the correlation between gun suicide ratio and survey-based gun ownership measures is entirely driven by the cross-sectional variation (Kovandzic et al., 2013; Kleck et al., 2016). This aspect invalidates a county-level panel analysis.

A reconciliation is to use a cross-sectional county-level analysis. Gun ownership can be confidently proxied by gun suicide ratio, which is highly correlated with survey-based measures as past research shows (Kleck, 2004; Azrael et al., 2004; Cook and Ludwig, 2006). However, working with county-level data brings other methodological challenges. First, homicide and homicide organ donor data are likely to exhibit overdispersion (the conditional variance being larger than the conditional mean of the variable) and excessive counts of zeros in the homicide organ donor supply variable. This requires methods such as the NB or the ZINB models, specifically tailored to deal with overdispersion and excessive counts of zeros, respectively. Second, there will be increased spatial dispersion in homicide organ donor supply at the county-level compared to a state-level analysis. Although state-level analysis wipes out most of the spatial dispersion through aggregation, it does so at the expense of introducing possibly severe aggregation bias to the extent of invalidating inference. For example, Dickert-Conlin et al. (2011) assess the impact of state motorcycle helmet laws on MVA donations using a state-level panel analysis. Close inspection shows that if MVA organ donor data had been collected at the county-level, 2612 out of 3105 counties in the contiguous US would not show a single case of MVA organ donor recovery in the 1994-2007 period. This means that, on average, 3.4 out of every 4 counties in the contiguous US did not recover any MVA organ donor. However, aggregation masks this overdispersion and sparsity and introduces bias when a very small number of counties in each state actually recover few MVA organ donors. The exact problem also jeopardizes Fernandez and Lang (2015)'s analysis with respect to suicide organ donor data. 


\subsection{Data and Sample}

For the reasons mentioned above, this study uses a cross-sectional design using county-level data, averaged over the 2009-2015 period. ${ }^{2}$ The sample includes all counties in the 48 states in the contiguous United States, excluding Bedford City and Clifton Forge, Virginia due to missing observations. This results in 3103 observations to be used in the analysis.

Gun homicides are retrieved from the Center for Disease Control - Wide-ranging Online Data for Epidemiologic Research (CDC-WONDER, 2018). Homicide organ donors are retrieved from the Health Resources and Services Administration - Organ Procurement and Transplantation Network (HRSA-OPTN, 2018). The latter data were not readily available at the county level. Therefore, the data are collected at the hospital level; the county where each hospital is located is identified and the cases are aggregated at the county level. Poverty rate, racial/ethnic composition and the age-interval-specific population measures are retrieved from the U.S Census Bureau. The gini index of income inequality and the adult percentage with a bachelor degree are obtained from U.S Census Bureau, the American Community Survey (ACS), two waves of 5-year estimates (2006-2010, 2011-2015). Unemployment rates are retrieved from the Bureau of Labor Statistics, Local Area Unemployment Statistics (LAUS) (BLS, 2019).

One of the most important measures that should be accounted for in gun policy studies to isolate the effect of gun control law is gun ownership. The reason is that the association between gun levels and gun laws arises from the political risks involved with introducing stricter gun control laws in areas of profound social gun culture and high gun ownership (Kleck et al., 2016). However, an uninterrupted time-series data on gun ownership are not available and the only available measures are based on General Social Survey conducted by the National Opinion Research Center in 2013 and in the 1973-2006 period, the survey conducted by the Behavioral Risk Factor Surveillance System for the 1992-1995 period and the surveys conducted on behalf of the Harvard Injury Control Research Center in 1996 and 1999 (Azrael et al., 2004). These surveys are representative at the national or at the state level and they are likely to produce unreliable estimates due to small sample size, response bias and inadequate response rates. However, ample evidence shows that the percentage of gun suicides is a valid proxy for gun ownership levels in cross-sectional studies. Information on total suicides and suicides committed by a gun are retrieved from the CDC-WONDER (2018) to calculate gun suicide ratio. The geographic distribution of gun homicide, homicide organ donor supply and gun ownership are given in Figure 1.

\footnotetext{
${ }^{2}$ The sample period begins in 2009 because it is the earliest year for which data on all covariates are available at the county level. The sample period ends in 2015 due to the time discrepancy between the data collection, analysis, the writing of the article and the submission. Note that the end year for the sample could have only extended to 2016 at the time of submission of this article because the strength index for gun control laws is available up to and including 2016. However, since the analysis in this paper is cross-sectional, the marginal cost of this extension is prohibitively greater than the additional insight one could have gained simply by extending the averaging period by one year.
} 
In order to account for the strength of state gun control laws, this study uses three interchangeable measures. The first measure, retrieved from Boston University, Center for Translational Epidemiology $\mathcal{E}^{3}$ Comparative Effectiveness Research (TEC, 2009), represents the strictness of the law for the year 2009. It involves an assessment of thirty-one policy dimensions and theoretically ranges between 0 and 32 . This measure is normalized over a scale between 0 and 100 where higher values indicate stricter gun control laws. The second alternative measure, retrieved from Giffords Law Center (Giffords, 2013), represents the strictness of the law for the year 2013 and involves an assessment of thirty policy dimensions. States receive points for each policy dimension for having effective laws and receive penalty for measures that increase the likelihood of gun violence. Based on point allocation, the total grade ranges between 0 and 100, where higher values indicate stricter gun control laws. ${ }^{3}$ The third and the final measure retrieved from Siegel et al. (2017a), contains an uninterrupted cross-section time-series information on the overall strength of state gun control laws for all 50 states for the 1991-2016 period. ${ }^{4}$ Using alternative state gun control law measures as the main covariate of interest in the analyses serves as a robustness check with respect to the size and the statistical significance of the effect of firearms regulation on gun homicides and homicide organ donor supply. It also serves to assess whether there is a significant intertemporal variation in state gun control laws to the extent of invalidating the use of a particular gun control measure.

Figure 2 shows the geographic distribution of the three measures of the strength of state gun control laws in the contiguous United States. The upper and middle panels show the geographic distribution of this index for the years 2009 and 2013, respectively. With respect to both measures, California has the most strict gun control laws, followed by Massachusetts (Connecticut) and New Jersey for the 2009 (2013) strength index. On the other end of the spectrum, Idaho and Utah (Arizona) has the least restrictive law for the 2009 (2013) strength index. With respect to the 2009 strength index, while only 10.4 percent $(5 / 48)$ of the states are located in the upper quintile, the bottom quintile hosts about 60.4 percent (29/48) of all states, showing an overly right-skewed distribution of the law. The last measure, whose geographic distribution is given in the lower panel of Figure of 2, is calculated by averaging the strength index of the law over the 2009-2015 period. Massachusetts has the most strict gun control laws, followed by California and Connecticut whereas Montana has the least restrictive laws followed by Vermont and Idaho. Notice that the geographic distribution of the index and the clustering patterns are extremely similar across all three measures even though they measure the strictness of the law at different points in time.

Information on state FPC laws is obtained from the United Network for Organ Sharing (UNOS) and Callison and Levin (2016). The adoption of state donor registry and the state donor designation share

\footnotetext{
${ }^{3}$ The definition of each of these policy dimensions, the point allocation and the grading system can be found at http://lawcenter.giffords.org/wp-content/uploads/2013/12/SCGLM-Final10-spreads-points.pdf

${ }^{4}$ Available at: http://www.statefirearmlaws.org
} 
are obtained from Donate Life America annual donor designation report cards (DLA, 2018). Due to the cross-sectional nature of the data, FPC laws and the adoption of donor registries measure the duration since the enactment of the law or the adoption of the registry, where higher values indicate earlier enactment or adoption.

Table 1 displays the descriptive statistics. Panel A displays the means and standard deviations for the overall sample, where the first two measures represent the outcome variables in terms of counts. Along with the outcome variables, a rich dataset is collected on a number of covariates that accounts for socioeconomic factors, racial and ethnic composition, laws and regulations regarding organ donation and demographic factors. With respect to state gun control laws, all three measures in Panel A exhibit fairly close means and standard deviations although they measure the strength of the law at different points in time and that each measure has been based on a similar but not exact set of policy dimensions and point allocation criteria. Using all three measures interchangeably in the analysis allows to assess whether their impacts on homicide rates and organ donations are significantly apart from one another.

Panel B of Table 1 displays the means and standard deviations of gun homicide and homicide organ donor supply rates and gun ownership by four equal intervals of the strength of gun control laws. There is a clear gradient of declining gun homicide rates except for the strictest 25 percent. For states with the most restrictive gun control laws, gun homicide rates show an increasing trend, exhibiting a mirrored-J pattern at the overall. On the other hand, homicide organ donor supply rates do not exhibit any detectable pattern by the strength of gun control laws. The clearest pattern is observed for gun ownership, proxied by gun suicide ratio. With respect to the strength of gun control laws, gun ownership exhibits a clear, declining gradient by increasing restrictiveness of the law. At the bottom of Panel B, the mean and standard deviations of the gun homicide and homicide organ donor rates and the gun control measures are given by four equal intervals of gun ownership. There is a clear gradient of escalating gun homicide rates by increasing gun levels. There is also a declining gradient of homicide organ donor supply by increasing gun levels although this is less clear. Consistent with the rest of Panel B, gun control laws exhibit a diminishing gradient by increasing gun levels. The overall picture in Table 1 shows that gun homicide rates tend to decrease by stricter gun control laws and decreasing gun levels and that lenient gun laws are associated with higher gun levels.

\subsection{Overdispersion in gun homicide}

Count data frequently occur in studies of death. The discrete nature of the distribution of the counts makes it difficult to produce approximately normal errors and the parameter estimates of linear models applied to count data are biased and inconsistent. A number of models such as the Poisson or the NB model has 
been used to model count outcomes. A common phenomenon of count data is that the conditional variance of the outcome variable may be greater than the conditional mean, known as overdispersion. Assessing the unconditional mean and the variance may be indicative of overdispersion. From Table 1, the variance-mean ratio for the number of gun homicide is $(127.34)^{2} / 25.66=632.93$. The variance of gun homicide count is greater than its mean, indicating that there might be overdispersion in the data. However, the interest is rather in determining whether this overdispersion disappears upon the inclusion of covariates.

Since we are ultimately interested in the effect of gun control laws and gun levels on organ supply, it is posited that the only way the law and gun ownership levels could affect homicide organ donors is through their effect on gun homicide rates. Therefore, one needs to assert that gun control laws and/or gun levels indeed affect gun homicides. For this purpose, a Poisson regression model is employed first, ignoring overdispersion, and used as a baseline for a less constrained model such as the NB which accounts for overdispersion (Cameron and Trivedi, 2013).

Gun homicide, $Y$, is assumed to follow a Poisson distribution, $Y_{i} \sim$ Poisson $\left(\mu_{i}\right)$ where $i$ denotes the county, $i=1,2, \ldots, N$ and $\mu_{i}$ is the expected number of gun homicide per unit of exposure, $t_{i}$, which is the county population. Then, the probability density function of gun homicide and the exponential mean function are respectively given by:

$$
\begin{gathered}
\operatorname{Pr}\left(Y_{i}=y_{i} \mid \mu_{i}, t_{i}\right)=\frac{e^{-\mu_{i} t_{i}}\left(\mu_{i} t_{i}\right)^{y_{i}}}{y_{i} !} \\
E\left[Y_{i} \mid \mathbf{x}_{i}\right]=\mu_{i}=t_{i} e^{\left(\mathbf{x}^{\prime}{ }_{i} \beta\right)}
\end{gathered}
$$

Taking the natural logarithm of equation (2) and rearranging yields a Poisson regression that is transformed into an analysis of rate of events per capita, given the offset variable $\ln \left(t_{i}\right)$, and a set of covariates $\mathbf{x}^{\prime}{ }_{i}:$

$$
\ln \left(\mu_{i}\right)=\ln \left(t_{i}\right)+\mathbf{x}_{i}{ }_{i} \beta
$$

The covariates in equation (3) consist of state gun control law, gun ownership, unemployment rate, gini index of income inequality, poverty rate, percentage of population with a bachelor degree, percentage of African-American, Native American and Hispanic population, population density, population share of age groups (0-19, 20-34, 35-44, 45-64), and county latitude and longitude.

Poisson model assumes equidispersion. In the presence of overdispersion, a more appropriate modeling strategy is to use a NB regression in which the number of gun homicides has extra-Poisson variation, captured 
by an additive omitted variable, $v_{i}$, whose exponentiation follows a Gamma distribution with mean $1 / \alpha$ and variance $\alpha: e^{v_{i}} \sim \operatorname{Gamma}\left(\frac{1}{\alpha}, \alpha\right)$. The probability mass function of gun homicide in the NB model is given by:

$$
\operatorname{Pr}\left(Y_{i}=y_{i} \mid \mu_{i}\right)=\frac{\Gamma\left(y_{i}+1 / \alpha\right)}{y_{i} ! \Gamma(1 / \alpha)}\left(\frac{1}{1+\alpha \mu_{i}}\right)^{\frac{1}{\alpha}}\left(\frac{\alpha \mu_{i}}{1+\alpha \mu_{i}}\right)^{y_{i}}
$$

Given the exposure variable $t_{i}$, the exponential mean function is given by:

$$
\mu_{i}=t_{i} e^{\left(\mathbf{x}^{\prime} \beta+v_{i}\right)}
$$

The NB model differs from the Poisson in the parameterization of dispersion. The dispersion and the variance in the negative binomial mean-dispersion model respectively are $1+\alpha e^{\left(\mathbf{x}^{\prime}{ }_{i} \beta+\ln \left(t_{i}\right)\right)}$ and $\mu+\alpha \mu^{2}$. When the dispersion parameter $\alpha=0$, the dispersion is 1 and the variance of Poisson and the NB model are equal to $\mu$, hence the model corresponds to a Poisson. The larger the dispersion parameter $\alpha$, the greater the overdispersion in the data.

\subsection{Excessive zero counts in homicide organ donor supply}

Homicide organ donor supply exerts an additional feature beyond simple overdispersion. The geographic distribution of homicide organ donor supply displayed in the bottom panel of Figure 1 along with its mean and variance in Table 1 shows overdispersion caused by excessive zeros. Table 4 shows a tabulation of these statistics. Of 3103 counties in the entire sample over the 2009-2015 period, a homicide organ donor recovery took place in 344 counties (about 11\% of the sample) only and the remaining 2759 counties did not recover any homicide donor. Under the presence of excessive counts of zeros and overdispersion, the variance of the parameter estimate is underestimated, leading to a false rejection of the null hypothesis. Modeling of excessive zeros is based on the assumption that there are two distinct processes that drive some counties to have no donor recovery and others to have positive recovery rates.

First, gun homicide is a prerequisite for homicide organ donor recovery. Hence there will be no homicide organ donor recovery without gun homicide. This type is referred to as a "structural" zeros. However, there may be zero homicide organ donor recovery, due to a multitude of other factors, even there are cases of gun homicide. This latter type is referred to as "at-risk" zeros. Therefore, the former types of zeros are caused by a structurally different phenomenon compared to the latter. Panel A of Table 4 shows that of the 2490 counties over the 2009-2015 period in which at least one case of gun homicide took place, only 343 (about 14\%) showed a homicide organ donor recovery. On the other hand, of the 613 counties where no gun 
homicide took place, there is only one county (Montour, PA) in which no gun homicide has been reported yet a total of five homicide organ donor recoveries took place in the sample period.

Second, homicide organ donor recovery is largely an urban phenomenon. Of all the 344 counties with at least one organ donor recovery in the sample, 98.84 percent $(340 / 344)$ are recovered in a county with an average population of at least 25,000 and 86.63 percent (298/344) are recovered in a county with an average population of at least 100,000. Expectedly, counties where homicide organ donor recovery takes place largely consist of urban areas and therefore it is likely that the occurence of excessive zeros is a structural phenomenon where a distinct process is at play. Notice that Panel B and Panel C of Table 4 also confirm that homicide organ donor recovery is an urban phenomenon.

To account for both overdispersion and excessive counts of zero in homicide organ donor supply, a ZINB model is estimated (Long, 1997; Hilbe, 2011). The ZINB maximizes a likelihood function that is a mixture of the logistic (or probit) and NB distributions where the former models the unobserved process that creates the excess zeros, and the latter models the counts. Respectively, the mean and the variance of the ZINB are $\mu=E(\tilde{Y})=\lambda(1-p)$ and $\operatorname{var}(\tilde{Y})=\mu+\left(\frac{p+\alpha}{1-p}\right) \mu^{2}$ where $\tilde{Y}$ is the homicide organ donor count, $\lambda$ is the mean of the underlying distribution, $p$ is the zero probability of recovering organ donor and $\alpha$ is the negative binomial overdispersion parameter. When $p=0$, the mean and the variance are $E(\tilde{Y})=\mu$ and $\operatorname{var}(\tilde{Y})=\mu+\alpha \mu^{2}$ and the model corresponds to a NB. When $\alpha=0$ (equidispersion), the model corresponds to a zero-inflated Poisson (ZIP).

The "urban effect" and the prerequisite for brain death suggest that whether a county recovers any homicide organ donor is likely to depend on whether it is urban and whether any case of gun homicide has been reported in that county. Therefore, the observable factors that determine the unobservable process that creates the excess zeros (i.e. the inflation or the zero-probability model) include an urban dummy that takes the value of 1 for all counties with an average population of at least 25,000 and a gun homicide dummy that takes the value of 1 for all counties with at least one case of gun homicide and 0 otherwise. The observable factors that determine the counts of homicide organ donors include all covariates as in section 3.2 and additionally includes covariates that are unrelated to homicide rates, such as state FPC law, state donor designation share and state adoption of donor registries. 


\section{Results}

\subsection{Effects on gun homicide}

The results of the Poisson model are given in Table 2. All specifications control for unemployment rate, poverty rate, income inequality, population share with a bachelor degree, African-American, American-Indian and Hispanic population shares, population density, population shares between 0-19, 20-34, 35-44 and 45-65 years of age and county longitude and latitude as spatial features. For traceability and space concerns and due to the focus on gun laws and gun levels, the parameter estimates of the above-mentioned covariates have been suppressed in the tables. However, the full results are available from the author.

Since gun homicide and homicide organ donor supply rates are defined as count/population, the model is adjusted by defining county population as the exposure variable from which cases of homicide occur. For ease of interpretation, all coefficients are exponentiated and reported as incidence rate ratio (IRR). Further, counties within states may share common unobservable characteristics, leading to inter-county error correlation within a state and underestimated standard errors. This would lead to over-rejection of the null of no effects on gun homicide. Therefore, standard errors are clustered at the state level. ${ }^{5}$

Panel A of Table 2 reports the results for the entire sample. Accordingly, more restrictive state gun control laws reduce the expected number of gun homicides by about 0.4 to 0.8 percent $((\operatorname{IRR}-1) \times 100)$. On the other hand, higher gun ownership reduces the expected number of gun homicides by about 0.8-0.9 percent. Two robustness checks assess whether the effects of state gun control laws and gun ownership substantially differ for urban and large urban counties. For this purpose, the sample is first restricted to urban counties with an average population of at least 25,000 and then to large urban counties with an average population of at least 100,000. The results are respectively reported in Panel B and C of Table 2. For the urban county sample, the effects of more restrictive state gun control laws and higher gun levels remain virtually unchanged. When the sample is restricted to large urban counties, the effects of gun ownership levels are no longer statistically different from zero in two thirds of the specifications at conventional test levels. Overall, the relationship between gun control laws and gun homicide in urban and large urban counties is highly consistent with that of the full sample, suggesting that more restrictive gun control laws are associated with a lower number of expected cases of gun homicide.

If the Poisson model is well specified and fits the data well, we expect the Pearson dispersion statistic (Pearson statistic divided by the degrees of freedom) to yield a value of 1 (Hilbe, 2011). However, the Pearson dispersion statistic, reported at the bottom of each Panel in Table 2, along with the Z-score and the

\footnotetext{
${ }^{5}$ Bootstrapping is an additional method used to adjust standard errors, particularly when the data is overdispersed (Hilbe, 2011). However, standard errors were much lower with bootstrapping than with state clustering. Therefore, clustered standard errors are reported.
} 
Lagrange multiplier (LM) statistics as additional diagnostic tests indicate that the Poisson model is highly overdispersed and does not fit the data well. ${ }^{6}$

A remedy is to estimate a model that takes overdispersion into account. Therefore, a NB model is estimated, whose results are reported in Table 3. Panel A shows the entire sample results and Panels B and $\mathrm{C}$ report those for urban and large urban counties, respectively. When overdispersion is appropriately taken into account, the IRRs for gun ownership levels are no longer statistically significantly different from zero at conventional test levels in the NB model. However, those of the state gun control laws, by and large, retain their significance albeit the effect size is attenuated. Notice that the Pearson dispersion statistic is lower than 1 in the NB model, indicating that the NB model exhibits underdispersion.

\subsection{Effects on homicide organ donor supply}

The NB model is robust to overdispersion; however it does not take into account the excessive counts of zeros in the homicide organ donor data. For this purpose, a ZINB model that accounts for both overdispersion and excessive counts of zeros is estimated, whose results are given in Panel A of Table 5. The main equation models the counts and the inflation equation models the unobserved process of excessive counts of zeros.

Panel A reports the results for the entire sample. Of the 3069 observations used, 2725 show a homicide organ donor count value of 0 . The main equation that corresponds to the NB model shows that among counties that recovered organ donors, stricter gun control laws decrease the expected number of homicide organ donors by 1.1 percent $((\operatorname{IRR}-1) \times 100)$ in columns (1) and (2) and by 0.7 percent in column (3). The estimates show that gun ownership decreases the expected number of homicide organ donors by about 2 percent across all three specifications.

The size of the overdispersion parameter $\alpha$, reported at the bottom of Panel A of Table 5 indicates negative binomial overdispersion in homicide organ donor data. The likelihood-ratio test for $\alpha=0$ allows us to compare the ZINB model against the ZIP that assumes equidispersion. The likelihood-ratio test statistic is statistically distinguishable from zero, indicating that the ZINB is preferable to ZIP.

On the other hand, the inflation equation models whether the counties do not recover homicide organ donors. Instead of directly interpreting the parameter estimates of the inflation equation, the average marginal effects (AME) are reported at the bottom of Table 5 to gain insight on how inflation equation affects the occurence of excessive zeros in homicide organ donor supply. Expectedly, the probability of recovering a homicide organ donor is higher by about 29 percentage points in counties with a population of

\footnotetext{
${ }^{6}$ The Z-score test is defined as $Z_{i}=\frac{\left(y_{i}-\mu_{i}\right)^{2}-y_{i}}{\mu_{i} \sqrt{2}} \sim t$ where $\mu_{i}$ are the fitted values of a Poisson regression. The LM test is defined as LM $=\frac{\sum_{i=1}^{n}\left(\mu_{i}^{2}-n \bar{y}_{i}\right)^{2}}{2 \sum_{i=1}^{n} \mu_{i}^{2}} \sim \chi_{1}^{2}$. The null hypothesis for both tests is that the Poisson model is not overdispersed. See Hilbe (2011), p:175-176.
} 
at least 25,000 and higher by about 21 percentage points if a case of gun homicide occurred in that county.

Again, panels B and C of Table 5 report the results for urban and large urban counties. Since these samples are restricted based upon average population size thresholds, it is apparent from Panel A of Table 4 that an urban dummy variable would fail to model the unobserved process of excessive counts of zeros. Further, due to the fact that organ donor recovery is largely an urban phenomenon, about 21 percent of urban counties and about 51 percent of large urban counties have at least one case of homicide organ donor recovery but this share in the entire sample is ony 11 percent. Based on Panels B and C of Table 4, about 97.2 percent of all urban counties and 99.7 percent of all large urban counties have at least once case of gun homicide. This suggests that when the sample is restricted to urban and large urban counties, only the "at-risk" zeros remain and the "structural" type of zeros is trivial. Hence these models are estimated by a NB instead of a ZINB. For both urban and large urban county samples, stricter gun control laws reduce the expected cases of homicide organ donor recovery in the range of 0.5 to 1.5 percent, depending on the gun control measure. On the other hand, the impact of gun ownership levels in the entire sample appears to be largely driven by urban counties, but no longer statistically distinguishable from zero when the sample is restricted to large urban counties. Both subsamples suggest that the NB model fits the data well, as evidenced by the Pearson dispersion statistic close to unity.

\section{Robustness Check}

Are gun control laws and gun levels unrelated to the supply of donors who die in circumstances other than homicide? To answer this question, a spurious outcome, known to be unrelated to gun control laws and gun levels is assigned. MVA and CVD organ donors are selected for this purpose and the data are collected by the same token as are collected for homicide organ donors. If gun control laws and gun levels are truly unrelated to MVA and CVD organ donor supply, then their effects on donor supply should be statistically indistinguishable from zero. Table 6 reports the results. The set of explanatory variables are the same as those reported in section 4, with the exception that the MVA organ donor supply model includes motorcycle

helmet law, seat belt law and state speed limits and the CVD organ donor supply model includes the 2002-2012 average of age-standardized diabetes prevalence as additional covariates.

Expectedly, state gun control laws do not exert a statistically significant impact on MVA or CVD organ donor supply. The only concern with these models is that gun ownership levels increase the expected cases of CVD organ donors as evidenced by a statistically distinguishable IRR greater than unity in Panel B. This raises doubts about the reliability on the impact of gun ownership levels on homicide organ donor supply. 


\section{Conclusion}

This study used county-level cross-sectional data to evaluate the effects of gun ownership and the unintended consequences of enforcing stricter state gun control laws on gun homicide rates and homicide organ donor supply. Two primary approaches to deal with count data have been invoked to control for overdispersion and/or excessive counts of zeros. The comparative summary results are given in Table 7. Panel A shows the implications of the impact of state gun control laws and gun ownership on gun homicides. While two thirds of the specifications for the entire sample finds no effect of state gun control laws on the expected cases of gun homicide, the NB results for the urban and large urban samples indicate that stricter laws generally lead to less homicide.

The comparative results regarding the testing of the central argument, that is, whether a transplantation paradox exists in the United States with respect to homicide organ donors, are given in Panel B of Table 7. For all interchangeable measures of the strength of state gun control law indices, stricter laws lead to less gun homicide and therefore to a lower supply of organ donors from victims of homicide. Taken together, the results, by and large, confirm the existence of a transplantation paradox hypothesis, that large-scale policy interventions to control the acquisition, the possession and the use of guns reduce the donor pool from victims of homicide by reducing gun homicides.

With respect to gun ownership on the other hand, all NB models point out to the conclusion that more guns do not affect gun homicides but the NB and the ZINB models show that higher gun ownership lowers the supply of organ donors from victims of homicide. If the only plausible way gun levels could affect homicide organ donors is through their effect on homicide rates, the size and the direction of the impact of gun levels should be regarded as inconclusive and unreliable. The robustness checks of section 5 also raise doubts about the reliability of the impact of gun ownership levels on homicide organ donor supply.

In order to increase the credibility of the findings, two types of robustness checks are performed to evaluate (1) whether gun control laws and gun levels retain their effects when the sample is restricted to urban and large urban counties and (2) whether gun control laws and gun levels are unrelated to the supply of donors who die in circumstances other than homicide. By using two spurious outcomes known to be unrelated to gun laws and gun levels, the results provided support for the restricting effect of gun control laws on homicide organ donor supply.

This study has several limitations. First, the assessment of the effect of the law only accounted for the inter-state variation in gun control laws. A complete assessment should account for the effect of local ordinances related to gun control to capture inter-county variation. For example, the strength index of gun control laws in the state of Maryland are about 2.31 to 2.87 times higher than the average strength index 
level for the entire US, depending on the gun control law measure used. However at the local level, Baltimore City for example enforces even stricter gun control laws than those of the state level. This study does not capture this type of local variation due to difficulties and impracticalities to collect local level, time-varying information on the strength of gun control laws for every county in the contiguous US. Even local data had been gathered, additional identification problems and data unavailability would have likely posed threats to valid inference.

Second, it might be argued that higher homicide cases may also lead to the passage of stricter local gun control ordinances or stricter state gun control laws. The passage of state gun control laws are likely to be sensitive to mass shootings that receive extensive media coverage and that trigger public consciousness rather than the overall levels of homicide, albeit stricter laws are not entirely caused by mass shootings (Kleck et al., 2016). Luca et al. (2020) finds that a single mass shooting leads to an approximately 15 percent increase in the number of firearm bills introduced within a state in the year after a mass shooting event and suggests using mass shootings as an instrument for gun control laws. However, mass shooting fatality rate is not proved to be a strong instrument due to its relative infrequency. Strikingly, the average gun homicide rate in Baltimore City is about 9.4 times higher than the average gun homicide rate in the state of Maryland in the 2009-2015 period. The implication of this striking local-vs.-state-level gap in the strictness of gun control laws and gun violence is that the local gun control laws may be driven by violence rates and are likely to be endogenous even though state gun control laws are unlikely to be affected by violence. This brings additional identification problems into any analysis that aims to evalute the effects of local gun control laws on violence in general and homicides in particular. Hence, an exogenous source of variation should be found to isolate the causal effects of the law at the local level. No such source of variation has been validated so far in the literature.

A third limitation of this study is the failure to account for the intertemporal variation in gun control laws although such data have been recently publicly available, thanks to the efforts of Siegel et al. (2017a). As discussed in section 3, accounting for the intertemporal variation in gun control laws via a longitudinal analysis is not without costs. A state-level panel analysis would suffer from serious aggregation bias due to the fact that organ donor recovery is extremely rare at the sub-state level from which the state-level aggregates are obtained.

A fourth limitation is the failure to account for the endogenous nature of gun ownership levels. That is, the fear of victimization induced by higher violence rates may drive up gun ownership levels (Kovandzic et al., 2012, 2013). The modeling strategy in this paper does not take into account the endogeneity of gun ownership due to this reverse causality and the results should be treated with caution. To account for the possibility that gun ownership may be endogenous to gun homicide and therefore to homicide organ donor 
supply, a source of exogenous variation should be found such that it might plausibly be viewed as random. It should be (strongly) correlated with gun ownership (i.e. relevant), should exhibit an impact on homicide rates through and only through gun levels and should not be directly related to homicide rates and homicide organ donor supply (i.e. excluded) or the errors of the model (i.e. clean). Altough prior research has used Republican or Democrat vote share in presidential elections (Kovandzic et al., 2012, 2013; Kleck et al., 2016; Bilgel, 2020) as instrument for gun ownership levels among others ${ }^{7}$ and suggested that it is a significant predictor of gun ownership (Cook and Ludwig, 1997, p. 35; Kleck, 1997, pp. 70-72), political conservatism is likely to be affected by the unobservables of these models, leaving the omitted variable bias problem intact. It should be noted that none of the parameter estimates of gun ownership showed homicide- or homicide organ donor-increasing effects (i.e. IRR $>1$ ) in any of the models despite the failure to account for its endogenous nature and the analysis reached conclusions similar to those that used instrumental variables methods (i.e. more guns, at least, do not mean more homicide).

The unique and the controversial nature of transplant medicine allows us to assess the unintended consequences of enforcing stricter gun control laws on homicide organ donor supply. The analysis confirms the transplantation paradox hypothesis and that gun control laws exacerbate the organ shortage in the United States. Although these costs are real, they are extremely small in magnitude relative to their benefits to be considered as pressing issues of health policy vis-à-vis the dire and the obvious consequences of gun decontrol. For those who wait on transplant list, weighing the costs to society of disarmament against the individual's right to keep and bear arms has something to offer. Until the day the transplant medicine no longer requires lost lives to save lives, the controversial aspects of social policy will preoccupy our minds.

\footnotetext{
${ }^{7}$ Other instruments used in the literature include outdoor/sports magazine subscription (Kovandzic et al., 2012), military veteran population and Guns \& Ammo magazine subscription (Kovandzic et al., 2013), Vietnam-era veteran population (Kleck et al., 2016) and hunting license rate (Bilgel, 2020).
} 


\section{References}

Annas, G.J. (1988): The paradoxes of organ transplantation. American Journal of Public Health, 78(6):621622.

Azrael, D.; P.J Cook; and M. Miller (2004): State and local prevalence of firearms ownership measurement, structure, and trends. Journal of Quantitative Criminology, 20(1):43-62.

Bilgel, F. (2020): Guns and homicides: a multiscale geographically weighted instrumental variables approach. Geographical Analysis, https://doi.org/10.1111/gean.12227:1-29.

Bilgel, F. and B. Galle (2015): Financial incentives for kidney donation: A comparative case study using synthetic controls. Journal of Health Economics, 43:103-117.

BLS (2019): Bureau of Labor Statistics, Local Area Unemployment Statistics (LAUS), 1999-2018. available at: https://www.bls.gov/data/, [last accessed: 13 April 2020].

Boulware, L.E.; M.U. Troll; L.C. Plantinga; and N.R. Powe (2008): The association of state and national legislation with living kidney donation rates in the United States: A National Study. American Journal of Transplantation, 8(7):1451-1470.

Callison, K. and A. Levin (2016): Donor registries, first-person consent legislation, and the supply of deceased organ donors. Journal of Health Economics, 49:70-75.

Cameron, A.C and P.K Trivedi (2013): Regression analysis of count data, vol. 53. Cambridge university press.

CDC-WONDER (2018): Centers for Disease Control and Prevention, Underlying Cause of Death, 1999-2018. available at: https://wonder.cdc.gov/ucd-icd10.html, [last accessed: 13 April 2020].

Chatterjee, P.; A.S. Venkataramani; A. Vijayan; J.R. Wellen; and E.G. Martin (2015): The effect of state policies on organ donation and transplantation in the United States. JAMA Internal Medicine, 175(8):13231329.

Cook, P.J. and J. Ludwig (1997): Guns in America: national survey on private ownership and use of firearms. US Department of Justice, Office of Justice Programs, National Institute of Justice.

Cook, P.J. and J. Ludwig (2006): The social costs of gun ownership. Journal of Public Economics, 90(1):379391. 
Dezhbakhsh, H. and P.H. Rubin (1998): Lives saved or lives lost? The effects of concealed-handgun laws on crime. The American Economic Review, 88(2):468-474.

Dickert-Conlin, S.; T. Elder; and B. Moore (2011): Donorcycles: Motorcycle helmet laws and the supply of organ donors. The Journal of Law and Economics, 54(4):907-935.

DLA (2018): Donate Life America, Annual Donor Designation Report Cards (2009-2015). available at: https://www.donatelife.net/mission-vision/, [last accessed: 13 April 2020].

Duggan, M. (2001): More guns, more crime. Journal of Political Economy, 109(5):1086-1114.

Fernandez, J. and M. Lang (2015): Suicide and organ donors: Spillover effects of mental health insurance mandates. Health Economics, 24(4):491-497.

Giffords (2013): Annual Gun Law Scorecard, 2013. Giffords Law Center, http://lawcenter.giffords.org.

Hahn, R.A.; A. Bilukha, O.and Crosby; M.T. Fullilove; A. Liberman; E. Moscicki; S. Snyder; F. Tuma; and P.A. Briss (2005): Firearms laws and the reduction of violence. American Journal of Preventive Medicine, $28(2): 40-71$.

Hepburn, L.M. and D. Hemenway (2004): Firearm availability and homicide: A review of the literature. Aggression and Violent Behavior, 9(4):417-440.

Hilbe, J.M. (2011): Negative binomial regression. Cambridge University Press.

Howard, D.H. and M.M. Byrne (2007): Should we promote organ donor registries when so few registrants will end up being donors? Medical Decision Making, 27(3):243-249.

HRSA-OPTN (2018): Health Resources and Services Administration, Organ Procurement and TransplantationServices. available at: https://optn.transplant.hrsa.gov/data/, [last accessed: 13 April 2020].

Irvin, N.; K. Rhodes; R. Cheney; and D. Wiebe (2014): Evaluating the effect of state regulation of federally licensed firearm dealers on firearm homicide. American Journal of Public Health, 104(8):1384-1386.

Kalesan, B.; M.E. Mobily; O. Keiser; J.A Fagan; and S. Galea (2016): Firearm legislation and firearm mortality in the USA: a cross-sectional, state-level study. The Lancet, 387(10030):1847-1855.

Kleck, G. (1997): Targeting guns: Firearms and their control. New York, NY: Aldine.

Kleck, G. (2004): Measures of gun ownership levels for macro-level crime and violence research. Journal of Research in Crime and Delinquency, 41(1):3-36. 
Kleck, G. (2015): The impact of gun ownership rates on crime rates: A methodological review of the evidence. Journal of Criminal Justice, 43(1):40-48.

Kleck, G.; T.V. Kovandzic; and J. Bellows (2016): Does gun control reduce violent crime? Criminal Justice Review, 41(4):488-513.

Kleck, G. and E.B. Patterson (1993): The impact of gun control and gun ownership levels on violence rates. Journal of Quantitative Criminology, 9(3):249-287.

Kovandzic, T.; M.E. Schaffer; and G. Kleck (2012): Gun Prevalence, Homicide Rates and Causality: A GMM Approach to Endogeneity Bias. In Gadd,D., Karstedt, S., Messner, S.F. (eds.) The SAGE Handbook of Criminological Research Methods. Thousand Oaks, CA: Sage.

Kovandzic, T.; M.E Schaffer; and G. Kleck (2013): Estimating the causal effect of gun prevalence on homicide rates: A local average treatment effect approach. Journal of Quantitative Criminology, 29(4):477-541.

Lacetera, N.; M. Macis; and S. S. Stith (2014): Removing Financial Barriers to Organ and Bone Marrow Donation: The Effect of Leave and Tax Legislation in the U.S. Journal of Health Economics, pp. 43-56.

Lang, M. (2013): The impact of mental health insurance laws on state suicide rates. Health Economics, $22(1): 73-88$.

Lee, L.K.; E.W. Fleegler; C. Farrell; E. Avakame; S. Srinivasan; D. Hemenway; and M.C. Monuteaux (2017): Firearm laws and firearm homicides: a systematic review. JAMA Internal Medicine, 177(1):106-119.

Long, J.S (1997): Regression models for categorical and limited dependent variables. Thousand Oaks, CA: Sage Publications.

Lott, J.R. and D.B. Mustard (1997): Crime, deterrence, and right-to-carry concealed handguns. The Journal of Legal Studies, 26(1):1-68.

Luca, M.; D. Malhotra; and C. Poliquin (2020): The impact of mass shootings on gun policy. Journal of Public Economics, 181:104083.

Moody, C.E. and T.B. Marvell (2005): Guns and crime. Southern Economic Journal, 71(4):720-736.

Osgood, D.W. (2000): Poisson-based regression analysis of aggregate crime rates. Journal of Quantitative Criminology, 16(1):21-43.

Peng, Y.; N. Vaidya; R. Finnie; J. Reynolds; C. Dumitru; G. Njie; R. Elder; R. Ivers; C. Sakashita; R.A. Shults; D.A. Sleet; R.P. Compton; et al. (2017): Universal motorcycle helmet laws to reduce injuries: a community guide systematic review. American Journal of Preventive Medicine, 52(6):820-832. 
Plassmann, F. and T.N. Tideman (2001): Does the right to carry concealed handguns deter countable crimes? Only a count analysis can say. The Journal of Law and Economics, 44(S2):771-798.

Rubin, P.H. and H. Dezhbakhsh (2003): The effect of concealed handgun laws on crime: beyond the dummy variables. International Review of Law and Economics, 23(2):199-216.

Ruddell, R. and G.L. Mays (2005): State background checks and firearms homicides. Journal of Criminal Justice, 33(2):127-136.

Siegel, M.; M. Pahn; C.S. Xuan, Z.and Ross; S. Galea; B. Kalesan; E. Fleegler; and K.A. Goss (2017a): Firearm-Related Laws in All 50 US States, 1991-2016. American Journal of Public Health, 107(0):11221129.

Siegel, M.; Z. Xuan; C.S. Ross; S. Galea; B. Kalesan; E. Fleegler; and K.A. Goss (2017b): Easiness of legal access to concealed firearm permits and homicide rates in the United States. American Journal of Public Health, 107(12):1923-1929.

Stolzenberg, L. and S.J. D'alessio (2000): Gun availability and violent crime: New evidence from the national incident-based reporting system. Social Forces, 78(4):1461-1482.

TEC (2009): Firearm Legislation, 2009 - data and codebook. Center for Translational Epidemiology \& Comparative Effectiveness Research(TEC), Boston University, http://sites.bu.edu/tec/our-services/availabledata/.

Venkataramani, A.S.; E.G. Martin; A. Vijayan; and J.R. Wellen (2012): The impact of tax policies on living organ donations in the United States. American Journal of Transplantation, 12(8):2133-2140.

Wellington, A.J. and E.A. Sayre (2011): An evaluation of financial incentives policies for organ donations in the United States. Contemporary Economic Policy, 29:1-13. 


\section{A Figures}

Figure 1: Geographic distribution of gun homicide, gun ownership and homicide organ donor supply

(a) Gun homicide count

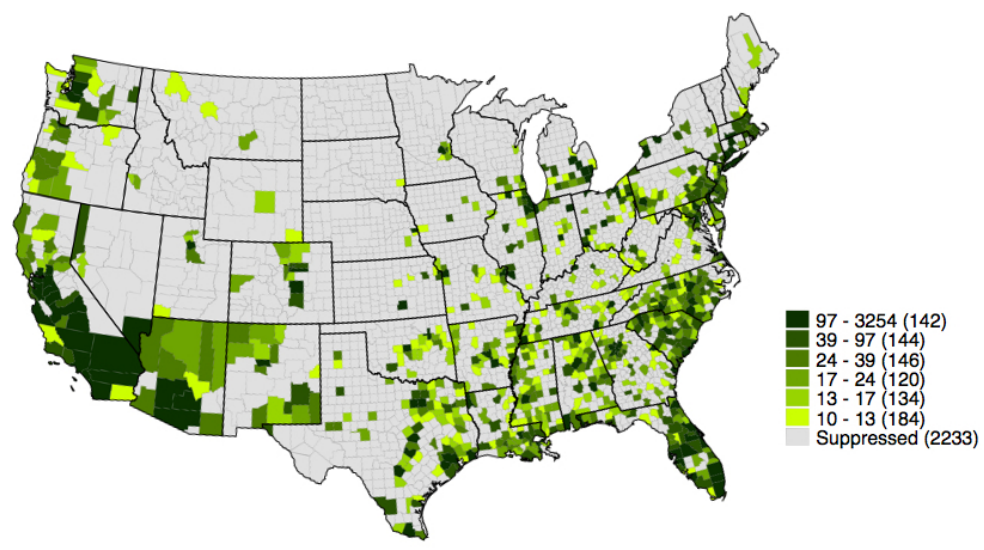

(b) Gun ownership

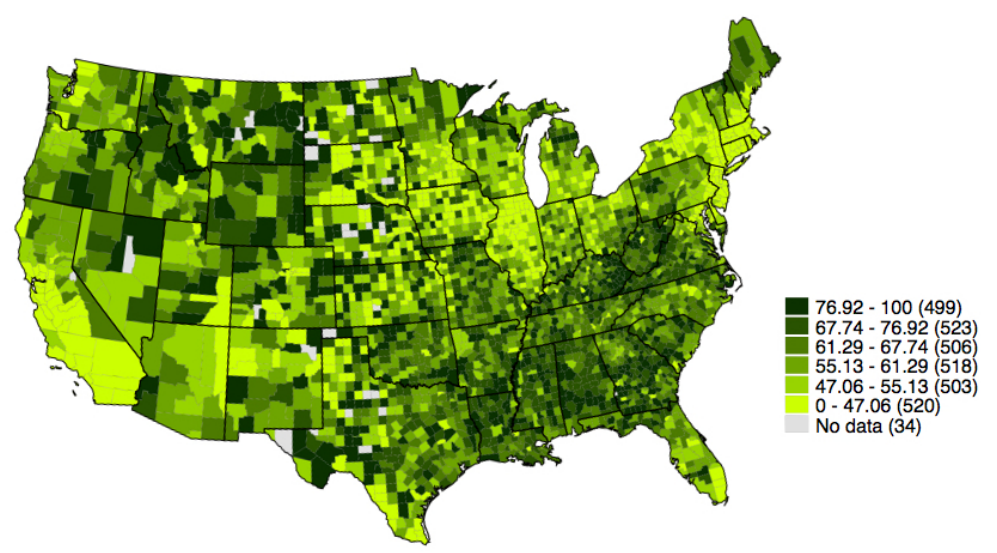

(c) Homicide organ donor count

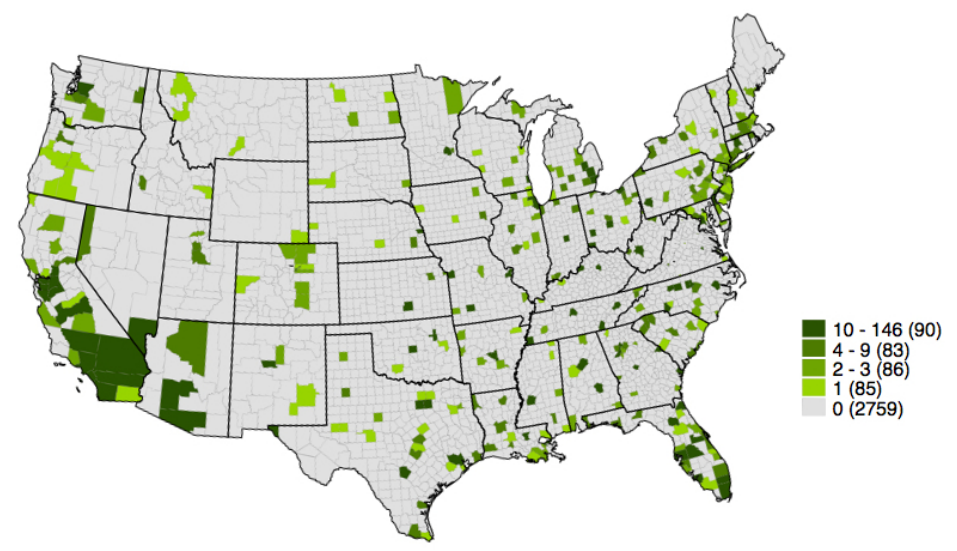

Notes: Gun ownership is expressed as percentage. Counties with less than 10 homicide counts are suppressed as per CDC-WONDER data use restrictions. 
Figure 2: Geographic distribution of the strength of state gun control laws

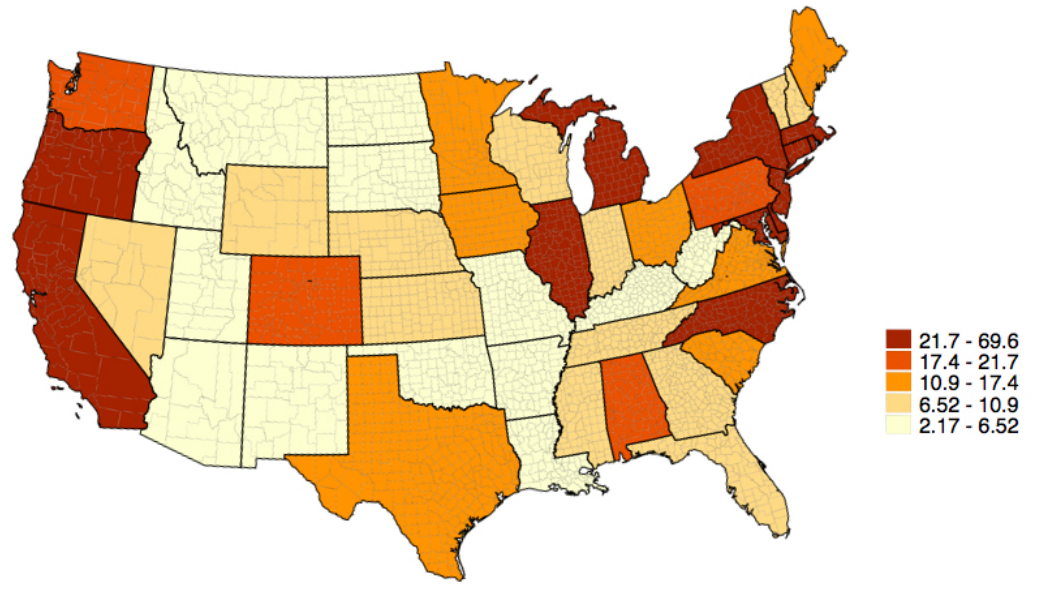

(a) Strength Index, 2009 (Boston University, TEC, 2009)

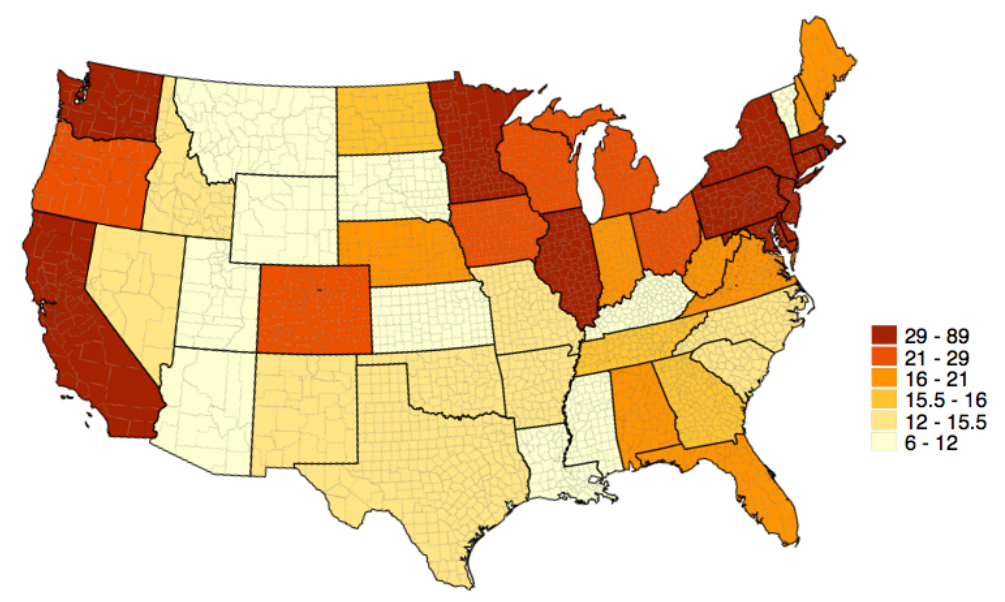

(b) Strength Index (Giffords Law Center, Giffords, 2013)

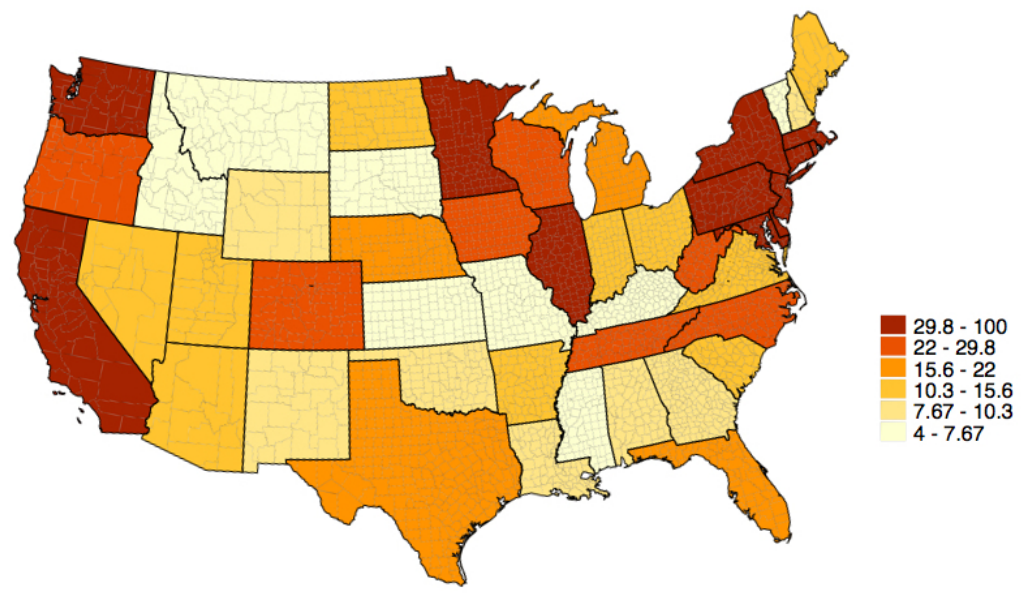

(c) Strength Index, 2009-2015 avg. (Siegel et al., 2017a) 


\section{B Tables}

Table 1: Descriptive statistics

\begin{tabular}{lcccllccc}
\hline Panel A: Overall means and standard deviations & & & \\
\hline Variable & mean (s.d) & $\min$ & $\max$ & Variable & mean (s.d) & $\min$ & $\max$ \\
\hline Gun homicide count & $25.66(127.34)$ & 0 & 3254 & Poverty rate, \% & $16.88(6.33)$ & 3.13 & 49.84 \\
Homicide organ donor count & $0.92(5.32)$ & 0 & 146 & Income inequality, 2006-2015 avg. & $0.44(0.03)$ & 0.32 & 0.60 \\
State Gun Control Law index & & & & Bachelor degree or higher, \% & $12.93(5.30)$ & 2.72 & 42.19 \\
$\quad$ TEC (2009) & $15.84(13.79)$ & 2.17 & 69.57 & African-American population, \% & $9.16(14.59)$ & 0 & 85.82 \\
$\quad$ Giffords (2013) & $23.34(17.96)$ & 6 & 89 & Native-American population, \% & $1.93(6.69)$ & 0 & 95.28 \\
$\quad$ Siegel et al. (2017a) & $21.42(19.27)$ & 4 & 100 & Hispanic population, \% & $8.58(13.37)$ & 0.09 & 95.84 \\
Gun ownership, \% & $61.32(17.54)$ & 0 & 100 & Population density & $260.6(1763.2)$ & 0.1371073 \\
First-person Consent Law & $8.86(3.45)$ & 3 & 21 & Population share (0-19 yrs), \% & $25.60(3.38)$ & 9.78 & 43.49 \\
Donor registry adoption & $13.51(5.09)$ & 5 & 27 & Population share (20-34 yrs), \% & $18.00(3.94)$ & 9.07 & 47.13 \\
Donor designation share, \% & $54.17(14.80)$ & 22.76 & 85.59 & Population share (35-44 yrs), \% & $11.83(1.50)$ & 5.92 & 19.15 \\
Unemployment rate, \% & $7.72(2.58)$ & 1.71 & 26.49 & Population share (45-64 yrs), \% & $27.76(3.00)$ & 8.38 & 42.02 \\
& & & & Population share (65+ yrs), \% & $16.81(4.22)$ & 3.75 & 45.46
\end{tabular}

Panel B: Means and standard deviations by the strictness of state gun control laws and gun levels

\begin{tabular}{lcccc}
\hline Variable & \multicolumn{4}{c}{ State gun control law (TEC, 2009) } \\
\hline & \multicolumn{3}{c}{ least restrictive } & \multicolumn{3}{c}{ \} \text { most restrictive } $\\
{$\cline { 2 - 5 } \text {$Gun homicide rate }} &{2.86(3.24)} &{2.39(2.97)} &{1.76(3.04)} &{2.08(2.20)} \\
{\text { Homicide organ donor rate }} &{0.03(0.11)} &{0.04(0.26)} &{0.06(0.11)} &{0.06(0.10)} \\
{\text { Gun ownership, \% }} &{63.37(17.44)} &{60.05(14.71)} &{48.01(13.06)} &{40.08(13.86)}$}
\end{tabular}

\begin{tabular}{lcccc}
\hline Variable & \multicolumn{3}{c}{ State gun control law (Giffords, 2013) } \\
\hline & \multicolumn{2}{c}{ least restrictive } & \multicolumn{2}{c}{ - most restrictive } \\
\cline { 2 - 3 } Gun homicide rate & $3.13(3.37)$ & $1.66(2.26)$ & $1.56(2.22)$ & $2.18(2.80)$ \\
Homicide organ donor rate & $0.03(0.12)$ & $0.04(0.25)$ & $0.02(0.08)$ & $0.06(0.12)$ \\
Gun ownership, \% & $65.29(17.22)$ & $57.67(14.39)$ & $47.21(13.14)$ & $41.54(14.08)$
\end{tabular}

\begin{tabular}{lcccc}
\hline Variable & \multicolumn{3}{c}{ State gun control law (Siegel et al., 2017a) } \\
\hline & \multicolumn{2}{c}{ least restrictive } & \multicolumn{2}{c}{ - most restrictive } \\
\cline { 2 - 3 } Gun homicide rate & $2.83(3.28)$ & $2.09(2.30)$ & $1.70(2.68)$ & $2.65(2.36)$ \\
Homicide organ donor rate & $0.03(0.15)$ & $0.04(0.22)$ & $0.04(0.10)$ & $0.08(0.12)$ \\
Gun ownership, \% & $63.76(17.17)$ & $59.16(14.55)$ & $45.01(13.81)$ & $41.22(13.90)$
\end{tabular}

\begin{tabular}{lcccc}
\hline Variable & \multicolumn{5}{c}{ Gun ownership } \\
\hline & \multicolumn{2}{c}{ least armed } & \multicolumn{3}{c}{$\longrightarrow$ most armed } \\
Gun homicide rate & $1.67(2.97)$ & $1.90(2.85)$ & $2.75(2.98)$ & $3.14(3.67)$ \\
Homicide organ donor rate & $0.03(0.08)$ & $0.04(0.14)$ & $0.03(0.16)$ & $0.01(0.18)$ \\
State Gun Control Law index & & & & \\
$\quad$ TEC (2009) & $26.18(23.65)$ & $23.27(19.31)$ & $13.91(10.47)$ & $10.84(6.39)$ \\
$\quad$ Giffords (2013) & $35.40(27.90)$ & $34.48(25.30)$ & $20.56(13.53)$ & $16.22(6.96)$ \\
$\quad$ Siegel et al. (2017a) & $34.76(31.30)$ & $32.49(26.47)$ & $18.85(14.96)$ & $13.68(8.82)$ \\
\hline
\end{tabular}

Notes: Gun homicide rate and homicide organ donor supply rate are expressed per 100,000 population. $N=3103$ for all variables except gun ownership for which $N=3069$. Gun homicide and homicide organ donor counts show the cumulative count in the 2009-2015 period. Gun ownership is proxied by the ratio of gun suicide to total suicide. First-person consent law (donor registry adoption) measures the average duration of the law (registry) in years. Standard deviations in parentheses. 
Table 2: Poisson estimates of the effect of gun control laws and gun ownership on gun homicides

\begin{tabular}{lccc}
\hline Outcome variable & \multicolumn{3}{c}{ Gun homicide count } \\
\cline { 2 - 4 } & $(1)$ & $(2)$ & $(3)$ \\
\hline Panel A: Entire Sample $(N=3069)$ & & & \\
State gun control laws & & & - \\
$\quad$ TEC (2009) & $0.992^{* * *}(0.002)$ & - & - \\
$\quad$ Giffords (2013) & - & $0.994^{* * *}(0.002)$ & - \\
$\quad$ Siegel et al. (2017a) & - & - & $0.996^{* * *}(0.002)$ \\
Gun ownership & $0.991^{* * *}(0.002)$ & $0.991^{* * *}(0.002)$ & $0.992^{* * *}(0.002)$ \\
\hline \hline Log pseudo-likelihood & -13897.1 & -13979.1 & -14062.6 \\
Akaike Information Criterion & 9.0675 & 9.1209 & 9.1753 \\
Pearson dispersion statistic & 5.998 & 6.060 & 6.101 \\
Z-score statistic [p-value] & $3.577^{* * *}(0.320)$ & $3.621^{* * *}(0.324)$ & $3.656^{* * *}(0.333)$ \\
LM statistic [p-value] & $20.35 \times 10^{6}[0.0000]$ & $20.18 \times 10^{6}[0.0000]$ & $20.06 \times 10^{6}[0.0000]$
\end{tabular}

Panel B: Urban counties $(N=1599)$

\begin{tabular}{lccc}
\hline State gun control laws & & & \\
TEC (2009) & $0.992^{* * *}(0.002)$ & - & - \\
Giffords (2013) & - & $0.994^{* * *}(0.002)$ & - \\
$\quad$ Siegel et al. (2017a) & - & - & $0.995^{* * *}(0.002)$ \\
Gun ownership & $0.990^{* * *}(0.003)$ & $0.990^{* * *}(0.003)$ & $0.991^{* * *}(0.003)$ \\
\hline \hline Log pseudo-likelihood & -10810.0 & -10867.0 & -10962.5 \\
Akaike Information Criterion & 13.5422 & 13.6135 & 13.7330 \\
Pearson dispersion statistic & 9.363 & 9.458 & 9.562 \\
Z-score statistic [p-value] & $3.518^{* * *}(0.297)$ & $3.565^{* * *}(0.303)$ & $3.597^{* * *}(0.312)$ \\
LM statistic [p-value] & $21.04 \times 10^{6}[0.0000]$ & $20.85 \times 10^{6}[0.0000]$ & $20.73 \times 10^{6}[0.0000]$
\end{tabular}

Panel C: Large urban counties $(N=579)$

\begin{tabular}{lccc}
\hline State gun control laws & & & \\
TEC (2009) & $0.994^{* * *}(0.002)$ & - & - \\
Giffords (2013) & - & $0.996^{* *}(0.002)$ & - \\
Siegel et al. (2017a) & - & - & $0.997^{*}(0.002)$ \\
Gun ownership & $0.994^{*}(0.003)$ & $0.994(0.004)$ & $0.996(0.004)$ \\
\hline \hline Log pseudo-likelihood & -6762.9 & -6820.6 & -6870.3 \\
Akaike Information Criterion & 23.4193 & 23.6187 & 23.7904 \\
Pearson dispersion statistic & 18.56 & 18.81 & 19.01 \\
Z-score statistic [p-value] & $3.764^{* * *}(0.270)$ & $3.808^{* * *}(0.280)$ & $3.887^{* * *}(0.290)$ \\
LM statistic [p-value] & $22.31 \times 10^{6}[0.0000]$ & $22.22 \times 10^{6}[0.0000]$ & $22.16 \times 10^{6}[0.0000]$ \\
\hline
\end{tabular}

Notes: The unit of observation is the county. All coefficients are reported as incidence rate ratio (IRR). Gun ownership is proxied by the ratio of gun suicides to total suicides. All specifications control for unemployment rate, poverty rate, income inequality, population share with a bachelor degree, African-American, American-Indian and Hispanic population shares, population density, population shares between 0-19, 20-34, 35-44 and 45-65 years of age and county longitude and latitude. All variables are averaged over the 2009-2015 period except gun control law (columns 1 and 2), income inequality and the population share with a bachelor degree. Income inequality and the population share with a bachelor degree are averaged over the 2006-2015 period. In all specifications, county population serves as the exposure variable. Standard errors in parentheses are clustered at the state level. The Z-score and LM report the test statistic and the p-value for the null hypothesis of no Poisson overdispersion. *, ** and *** denote statistical significance at the 10,5 and 1 percent level respectively. 
Table 3: NB estimates of the effect of gun control laws and gun ownership on gun homicides

\begin{tabular}{|c|c|c|c|}
\hline \multirow[t]{2}{*}{ Outcome variable } & \multicolumn{3}{|c|}{ Gun homicide count } \\
\hline & (1) & $(2)$ & $(3)$ \\
\hline \multicolumn{4}{|c|}{ Panel A: Entire Sample $(N=3069)$} \\
\hline \multicolumn{4}{|c|}{ State gun control laws } \\
\hline TEC (2009) & $0.997(0.002)$ & - & - \\
\hline Giffords (2013) & - & $0.997^{*}(0.001)$ & - \\
\hline Siegel et al. (2017a) & - & - & $0.998(0.001)$ \\
\hline Gun ownership & $0.999(0.002)$ & $0.999(0.002)$ & $0.999(0.002)$ \\
\hline Log pseudo-likelihood & -7832.1 & -7832.0 & -7834.3 \\
\hline Akaike Information Criterion & 5.4593 & 5.4593 & 5.4597 \\
\hline Pearson dispersion statistic & 0.471 & 0.471 & 0.471 \\
\hline Overdispersion parameter, $\alpha$ & $0.240^{* * *}(0.020)$ & $0.240^{* * *}(0.020)$ & $0.241^{* * *}(0.020)$ \\
\hline \multicolumn{4}{|c|}{ Panel B: Urban counties $(N=1599)$} \\
\hline \multicolumn{4}{|c|}{ State gun control laws } \\
\hline TEC (2009) & $0.996^{*}(0.002)$ & - & - \\
\hline Giffords (2013) & - & $0.997^{* *}(0.001)$ & - \\
\hline Siegel et al. (2017a) & - & - & $0.998^{*}(0.001)$ \\
\hline Gun ownership & $0.998(0.002)$ & $0.997(0.002)$ & $0.998(0.002)$ \\
\hline Log pseudo-likelihood & -5847.7 & -5847.6 & -5848.2 \\
\hline Akaike Information Criterion & 7.3355 & 7.3353 & 7.3361 \\
\hline Pearson dispersion statistic & 0.291 & 0.292 & 0.292 \\
\hline Overdispersion parameter, $\alpha$ & $0.205^{* * *}(0.017)$ & $0.205^{* * *}(0.017)$ & $0.206^{* * *}(0.017)$ \\
\hline \multicolumn{4}{|c|}{ Panel C: Large urban counties $(N=579)$} \\
\hline \multicolumn{4}{|c|}{ State gun control laws } \\
\hline TEC (2009) & $0.996^{*}(0.002)$ & - & - \\
\hline Giffords (2013) & - & $0.997^{*}(0.002)$ & - \\
\hline Siegel et al. (2017a) & - & - & $0.998(0.001)$ \\
\hline Gun ownership & $0.997(0.003)$ & $0.997(0.003)$ & $0.998(0.003)$ \\
\hline Log pseudo-likelihood & -2794.9 & -2794.9 & -2795.2 \\
\hline Akaike Information Criterion & 9.7130 & 9.7131 & 9.7139 \\
\hline Pearson dispersion statistic & 0.217 & 0.218 & 0.218 \\
\hline Overdispersion parameter, $\alpha$ & $0.180^{* * *}(0.017)$ & $0.180^{* * *}(0.017)$ & $0.181^{* * *}(0.017)$ \\
\hline
\end{tabular}

Notes: The unit of observation is the county. All coefficients are reported as incidence rate ratio (IRR). Gun ownership is proxied by the ratio of gun suicides to total suicides. All specifications control for unemployment rate, poverty rate, income inequality, population share with a bachelor degree, African-American, American-Indian and Hispanic population shares, population density, population shares between 0-19, 20-34, 35-44 and 45-65 years of age and county longitude and latitude. All variables are averaged over the 2009-2015 period except gun control law (columns 1 and 2), income inequality and the population share with a bachelor degree. Income inequality and the population share with a bachelor degree are averaged over the 2006-2015 period. In all specifications, county population serves as the exposure variable. Standard errors in parentheses are clustered at the state level. ${ }^{*}, * *$ and $* * *$ denote statistical significance at the 10,5 and 1 percent level respectively. 
Table 4: Tabulation of gun homicides and homicide organ donors

Panel A: Entire sample

\begin{tabular}{c|ccc} 
& \multicolumn{3}{|c}{$\begin{array}{l}\text { Homicide organ } \\
\text { donor indicator }\end{array}$} \\
$\begin{array}{c}\text { Gun homicide } \\
\text { indicator }\end{array}$ & 0 & 1 & Total \\
\hline 0 & 612 & 1 & 613 \\
1 & 2147 & 343 & 2490 \\
\hline Total & 2759 & 344 & 3103
\end{tabular}

Panel B: Urban counties

\begin{tabular}{c|ccc} 
& \multicolumn{3}{|c}{$\begin{array}{l}\text { Homicide organ } \\
\text { donor indicator }\end{array}$} \\
$\begin{array}{c}\text { Urban } \\
\text { indicator }\end{array}$ & 0 & 1 & Total \\
\hline 0 & 1500 & 4 & 1504 \\
1 & 1259 & 340 & 1599 \\
\hline Total & 2759 & 344 & 3103
\end{tabular}

\section{Panel C: Large urban counties}

\begin{tabular}{c|ccc} 
& \multicolumn{3}{|c}{$\begin{array}{l}\text { Homicide organ } \\
\text { donor indicator }\end{array}$} \\
$\begin{array}{c}\text { Gun homicide } \\
\text { indicator }\end{array}$ & 0 & 1 & Total \\
\hline 0 & 45 & 0 & 45 \\
1 & 1214 & 340 & 1554 \\
\hline Total & 1259 & 340 & 1599
\end{tabular}

\begin{tabular}{c|ccc} 
& \multicolumn{3}{|c}{$\begin{array}{l}\text { Homicide organ } \\
\text { donor indicator }\end{array}$} \\
$\begin{array}{c}\text { Gun homicide } \\
\text { indicator }\end{array}$ & 0 & 1 & Total \\
\hline 0 & 2 & 0 & 2 \\
1 & 279 & 298 & 577 \\
\hline Total & 281 & 298 & 579
\end{tabular}


Table 5: NB estimates of the effect of gun control laws and gun ownership on homicide organ donors

\begin{tabular}{|c|c|c|c|}
\hline \multirow[t]{2}{*}{ Outcome variable } & \multicolumn{3}{|c|}{ Homicide organ donor count } \\
\hline & $(1)$ & $(2)$ & $(3)$ \\
\hline \multicolumn{4}{|c|}{ Panel A: Entire Sample, zero-inflated } \\
\hline \multicolumn{4}{|c|}{$\left(N=3069, N_{0}=2725\right)$} \\
\hline \multicolumn{4}{|l|}{ Main equation } \\
\hline \multicolumn{4}{|l|}{ State gun control laws } \\
\hline TEC (2009) & $0.989^{* *}(0.005)$ & - & - \\
\hline Giffords (2013) & - & $0.989^{* *}(0.005)$ & - \\
\hline Siegel et al. (2017a) & - & - & $0.993^{*}(0.004)$ \\
\hline Gun ownership & $0.980^{* *}(0.010)$ & $0.978^{* *}(0.010)$ & $0.981 *(0.010)$ \\
\hline \multicolumn{4}{|l|}{ Inflation equation } \\
\hline Urban dummy & $0.007^{* * *}(0.007)$ & $0.007^{* * *}(0.007)$ & $0.007^{* * *}(0.007)$ \\
\hline Gun homicide dummy & $0.027(0.067)$ & $0.027(0.067)$ & $0.026(0.067)$ \\
\hline \multicolumn{4}{|l|}{ Average marginal effects } \\
\hline Urban dummy & $-0.292^{* * *}(0.079)$ & $-0.292^{* * *}(0.078)$ & $-0.290^{* * *}(0.079)$ \\
\hline Gun homicide dummy & $-0.211^{* *}(0.088)$ & $-0.211^{* *}(0.089)$ & $-0.210^{* *}(0.088)$ \\
\hline Log pseudo-likelihood & -1382.6 & -1381.2 & -1383.5 \\
\hline Overdispersion parameter, $\alpha$ & $1.253^{* * *}(0.257)$ & $1.244^{* * *}(0.252)$ & $1.276^{* * *}(0.257)$ \\
\hline Likelihood ratio test $(\alpha=0)$ & $392.36^{* * *}$ & $393.04^{* * *}$ & $398.77^{* * *}$ \\
\hline \multicolumn{4}{|c|}{ Panel B: Urban counties $(N=1599)$} \\
\hline \multicolumn{4}{|c|}{ State gun control laws } \\
\hline TEC (2009) & $0.985^{* * *}(0.005)$ & - & - \\
\hline Giffords (2013) & - & $0.986^{* * *}(0.004)$ & - \\
\hline Siegel et al. (2017a) & - & - & $0.990^{* * *}(0.003)$ \\
\hline Gun ownership & $0.971^{* * *}(0.006)$ & $0.968^{* * *}(0.007)$ & $0.971^{* * *}(0.007)$ \\
\hline Log pseudo-likelihood & -1328.5 & -1326.8 & -1330.3 \\
\hline Akaike Information Criterion & 1.6866 & 1.6845 & 1.6890 \\
\hline Pearson dispersion statistic & 1.006 & 0.961 & 0.978 \\
\hline Overdispersion parameter, $\alpha$ & $1.336^{* *}(0.186)$ & $1.329^{* *}(0.182)$ & $1.361^{* *}(0.186)$ \\
\hline \multicolumn{4}{|c|}{ Panel C: Large urban counties $(N=579)$} \\
\hline \multicolumn{4}{|c|}{ State gun control laws } \\
\hline TEC (2009) & $0.990^{* *}(0.004)$ & - & - \\
\hline Giffords (2013) & - & $0.991^{* *}(0.003)$ & - \\
\hline Siegel et al. (2017a) & - & - & $0.995^{* *}(0.003)$ \\
\hline Gun ownership & $0.987(0.009)$ & $0.985(0.010)$ & $0.989(0.010)$ \\
\hline Log pseudo-likelihood & -1053.4 & -1052.9 & -1054.1 \\
\hline Akaike Information Criterion & 3.7077 & 3.7059 & 3.7102 \\
\hline Pearson dispersion statistic & 1.161 & 1.108 & 1.132 \\
\hline Overdispersion parameter, $\alpha$ & $0.761^{* *}(0.104)$ & $0.760^{* *}(0.103)$ & $0.771^{*}(0.104)$ \\
\hline
\end{tabular}

Notes: The unit of observation is the county. All coefficients are reported as incidence rate ratio (IRR). Gun ownership is proxied by the ratio of gun suicides to total suicides. All specifications control for FPC law, adoption of donor registry, donor designation share, unemployment rate, poverty rate, income inequality, population share with a bachelor degree, African-American, American-Indian and Hispanic population shares, population density, population shares between 0-19, 20-34, 35-44 and 45-65 years of age and county longitude and latitude. All variables are averaged over the 2009-2015 period except gun control law (columns 1 and 2), FPC law, donor designation share, donor registry adoption, income inequality and the population share with a bachelor degree. Income inequality and the population share with a bachelor degree are averaged over the 2006-2015 period. Donor designation share is averaged over the 2012-2015 period. FPC law and donor registry adoption measure the duration of the law in the sample. In all specifications, county population serves as the exposure variable. Urban dummy equals 1 if the average county population is at least 25,000 and 0 otherwise. Gun homicide dummy equals 1 if a case of gun homicide occurs and 0 otherwise. Average marginal effects report the change in the probability of not recovering a homicide organ donor. Standard errors in parentheses are clustered at the state level. ${ }^{*}, * *$ and ${ }^{* * *}$ denote statistical significance at the 10 , 5 and 1 percent level respectively. 
Table 6: Spurious outcome: effects of gun control laws and gun ownership on MVA and CVD organ donors

\begin{tabular}{|c|c|c|c|}
\hline Panel A: MVA organ donor count & (1) & $(2)$ & $(3)$ \\
\hline \multicolumn{4}{|l|}{ Main equation } \\
\hline \multicolumn{4}{|l|}{ State gun control laws } \\
\hline TEC (2009) & $0.998(0.007)$ & - & - \\
\hline Giffords (2013) & - & $0.998(0.005)$ & - \\
\hline Siegel et al. (2017a) & - & - & $0.999(0.004)$ \\
\hline Gun ownership & $1.018(0.014)$ & $1.018(0.015)$ & $1.018(0.015)$ \\
\hline \multicolumn{4}{|l|}{ Inflation equation } \\
\hline Urban dummy & $0.090^{* * *}(0.037)$ & $0.090^{* * *}(0.037)$ & $0.090^{* * *}(0.037)$ \\
\hline MVA count & $0.974^{* * *}(0.003)$ & $0.975^{* * *}(0.003)$ & $0.974^{* * *}(0.003)$ \\
\hline \multicolumn{4}{|l|}{ Average marginal effects } \\
\hline Urban dummy & $-0.200^{* * *}(0.035)$ & $-0.200^{* * *}(0.035)$ & $-0.200^{* * *}(0.035)$ \\
\hline MVA count & $-0.002^{* * *}(0.0003)$ & $-0.002^{* * *}(0.0003)$ & $-0.002^{* * *}(0.0003)$ \\
\hline Log pseudo-likelihood & -2124.8 & -2124.7 & -2124.8 \\
\hline Overdispersion parameter, $\alpha$ & $1.315^{* * *}(0.305)$ & $1.315^{* * *}(0.304)$ & $1.316^{* * *}(0.307)$ \\
\hline Likelihood ratio test $(\alpha=0)$ & $2461.92^{* * *}$ & $2469.18^{* * *}$ & $2471.62^{* * *}$ \\
\hline Panel B: CVD organ donor count & $(1)$ & $(2)$ & $(3)$ \\
\hline \multicolumn{4}{|l|}{ Main equation } \\
\hline \multicolumn{4}{|l|}{ State gun control laws } \\
\hline TEC (2009) & $0.993(0.005)$ & - & - \\
\hline Giffords (2013) & - & $0.994(0.004)$ & - \\
\hline Siegel et al. (2017a) & - & - & $0.996(0.003)$ \\
\hline Gun ownership & $1.020^{* *}(0.010)$ & $1.020^{* *}(0.009)$ & $1.021^{* *}(0.010)$ \\
\hline \multicolumn{4}{|l|}{ Inflation equation } \\
\hline Urban dummy & $0.462^{* *}(0.166)$ & $0.461^{* *}(0.165)$ & $0.459^{* *}(0.164)$ \\
\hline CVD count & $0.994^{* * *}(0.001)$ & $0.994^{* * *}(0.001)$ & $0.994^{* * *}(0.001)$ \\
\hline \multicolumn{4}{|l|}{ Average marginal effects } \\
\hline Urban dummy & $-0.065^{* *}(0.031)$ & $-0.065^{* *}(0.030)$ & $-0.065^{* *}(0.030)$ \\
\hline CVD count & $-0.0005^{* * *}(0.00006)$ & $-0.0005^{* * *}(0.00006)$ & $-0.0004^{* * *}(0.00006)$ \\
\hline Log pseudo-likelihood & -3120.2 & -3120.2 & -3121.0 \\
\hline Overdispersion parameter, $\alpha$ & $1.198^{* * *}(0.144)$ & $1.198^{* * *}(0.144)$ & $1.199^{* * *}(0.143)$ \\
\hline Likelihood ratio test $(\alpha=0)$ & $6336.35^{* * *}$ & $6346.96^{* * *}$ & $6384.67^{* * *}$ \\
\hline
\end{tabular}

Notes: The unit of observation is the county. $N=3069, N_{0}^{M V A}=2660, N_{0}^{C V D}=2410$. All coefficients in the main equation are reported as incidence rate ratio (IRR). Gun ownership is proxied by the ratio of gun suicides to total suicides. All specifications control for FPC law, adoption of donor registry, donor designation share, unemployment rate, poverty rate, income inequality, population share with a bachelor degree, African-American, American-Indian and Hispanic population shares, population density, population shares between 0-19, 20-34, 35-44 and 45-65 years of age and county longitude and latitude. MVA organ donor model additionally controls for motorcycle helmet law, seat belt law and state speed limit (mph). CVD organ donor model additionally controls for diabetes prevalence. All variables are averaged over the 2009-2015 period except gun control law (columns 1 and 2), FPC law, motorcycle helmet law, seat belt law, donor designation share, donor registry adoption, income inequality and the population share with a bachelor degree. Income inequality and the population share with a bachelor degree are averaged over the 2006-2015 period. Donor designation share is averaged over the 2012-2015 period. FPC law and donor registry adoption measure the duration of the law in the sample. In all specifications, county population serves as the exposure variable. Urban dummy equals 1 if the average county population is at least 25,000 and 0 otherwise. Average marginal effect report the change in the probability of not recovering a MVA or CVD organ donor. Standard errors in parentheses are clustered at the state level. MVA: motor vehicle accident. CVD: cerebrovascular disease. ${ }^{*}, * *$ and ${ }^{* * *}$ denote statistical significance at the 10,5 and 1 percent level respectively. 
Table 7: Comparative summary results

\section{Panel A: Gun homicide}

Entire sample $\quad$ Urban counties $\quad$ Large urban counties

Stricter laws lead to...
TEC (2009)

Giffords (2013)

Siegel et al. (2017a)

More guns lead to...

$\begin{array}{ccc} & & \\ \text { no } \text { effect } & \text { less homicide } & \text { less homicide } \\ \text { less homicide } & \text { less homicide } & \text { less homicide } \\ \text { no effect } & \text { less homicide } & \text { no effect } \\ \text { no effect } & \text { no effect } & \text { no effect }\end{array}$

Panel B: Homicide organ donor supply

\begin{tabular}{|c|c|c|c|}
\hline \multirow[b]{2}{*}{ Stricter laws lead to... } & Entire sample & Urban counties & Large urban counties \\
\hline & & & \\
\hline TEC (2009) & lower donor supply & lower donor supply & lower donor supply \\
\hline Giffords (2013) & lower donor supply & lower donor supply & lower donor supply \\
\hline Siegel et al. (2017a) & lower donor supply & lower donor supply & lower donor supply \\
\hline More guns lead to... & lower donor supply & lower donor supply & no effect \\
\hline
\end{tabular}

